\title{
To Boldly Remember Where We Have Already Been
}

\section{Revisiting the Cutter Polio Vaccine Incident during Operation Warp Speed}

\author{
Nathaniel L. Moir \\ Ernest May Postdoctoral Fellow in History and Policy, John F. Kennedy \\ School of Government, Harvard University, Cambridge, MA, USA \\ nmoir@hks.harvard.edu \\ Received July 2020 | Accepted September 2020 | \\ Published online September 28, 2020
}

\begin{abstract}
This article revisits the Cutter Incident in the United States in April 1955 when massproduced doses of polio vaccine containing insufficiently inactivated (killed) live polio virus were released to the U.S. public. The Cutter Incident also affected subsequent vaccine development and these lessons remain relevant in the international quest to create a rapidly developed vaccine for Covid-19. The Cutter Incident shows how things can go wrong when a vaccine is manufactured in haste and without adequate safety precautions during mass-production. In the article's later section, liability without fault, among other consequences resulting from the incident, are also assessed in the context of current vaccine development through Operation Warp Speed, the public-private partnership funded by the U.s. government to develop a remedy for COVID-19.
\end{abstract}

\section{Keywords}

COVID-19 - SARS-CoV-2 - polio - vaccine - Cutter Laboratories 
The federal government inspects meat in the slaughterhouses more carefully than it has examined the polio vaccine.

Senator WAYNE MORSE 1

The vaccine was packed and ready for delivery. After many months of feverish development to find a cure, hundreds of boxes, each containing thousands of tiny glass bottles filled with a desperately-sought solution, waited for shipment across the country. In 1954, five drug companies, Eli Lilly, Parke-Davis, Wyeth, Pitman-Moore, and Cutter Laboratories devoted their effort to producing mass lots of polio vaccine using a procedure Jonas Salk, M.D. had successfully devised through which the polio virus was killed - technically known as inactivationwith formaldehyde. ${ }^{2}$ From these mass lots of vaccine, "samples of the inactivated polio vaccine were then sent to the National Institute of Health's Laboratory of Biologic Control, which was responsible for certifying that the vaccines were indeed inactivated and safe for use." ${ }^{3}$ At one of the companies developing these vaccines, Cutter Laboratories of Berkeley, California, numerous samples were tested by a scientist, Dr. Bernice Eddy. Eddy began inoculating monkeys with samples from five lots of vaccines and when one animal demonstrated signs of paralysis, this indicated that vaccines in the mass-produced inventory had not been properly inactivated. After reporting this problem to the National Institute of Health, Eddy received no response.

In April 1955, as the first company on the market with the polio vaccine and as a reward to its employees, "Cutter executives cleared the company cafeteria, brought in nurses, and gave the vaccine to the children of 450 employees." ${ }^{\prime 4}$ Over

1 As quoted in Paul A. Offit, M.D., The Cutter Incident: How America's First Polio Vaccine Led to the Growing Vaccine Crisis (New Haven: Yale University Press, 2005), 118.

2 Paul A. Offit, M.D. “The Cutter Incident, 50 Years Later." The New England Journal of Medicine 352 (14) (2005), 1411.

3 Robert Gallo, M.D., Virus Hunting:AIDS, Cancer, and the Human Retrovirus: A Story of Scientific Discovery (New York: Basic Books, 1991), 28.

4 Paul A. Offit, M.D., The Cutter Incident: How America's First Polio Vaccine Led to the Growing Vaccine Crisis (New Haven: Yale University Press, 2005), 77. 
the course of the next two weeks, 380 ,ooo doses Cutter produced were administered across several western states including California, Idaho, and Arizona. ${ }^{5}$ After multiple reports of paralysis in children appeared, the Epidemic Intelligence Service determined on April 27, 1955 that "two production pools made by Cutter Laboratories accounting for 120,000 doses contained live polio virus." ${ }^{6}$ The same day, United States Surgeon General, Leonard Scheele, issued a recall for all Cutter vaccines and Cutter immediately complied.

The damage was already done and was seeping through all too many children, mostly 1st and 2nd graders who were prioritized because of their risk to natural polio infection. By April 30, according to Paul A. Offit, M.D., and "within forty-eight hours of the recall, Cutter's vaccine had paralyzed or killed twenty-five children; fourteen in California, seven in Idaho, two in Washington, one in Illinois, and one in Colorado"7 Worse, the vaccine also created an epidemic because of polio's contagious nature. According to Robert Gallo, M.D., "Eighty children received active vaccine" and "harboring active virus, presumably through inoculation, they passed it on to approximately 120 additional people with whom they came in contact. By the time the error was discovered, three-quarters of the victims had been paralyzed and eleven had died."

Among those who had their own children vaccinated, Cutter employees' trust in their product was as implicit as it was problematic. "'We panicked,' said Frank Deromedi, a Cutter employee who worked on production and who had immunized his sons, Dennis, age eight and Craig, age five. 'After all, our kids had been vaccinated." "9 As the Cutter Incident unfolded, it became the most consequential, self-produced medical calamity Americans endured in the twentiethcentury. According to Offit, author and Director of the Vaccine Education Center and Professor of Pediatrics at Children's Hospital of Philadelphia, "It was one of the worst biological disasters in American history, it exploded the myth of the invulnerability of science and destroyed faith in the vaccine enterprise."10

$5 \quad$ Ibid., 82.

6 Paul A. Offit, M.D. "The Cutter Incident, 5o Years Later." The New England Journal of Medicine 352 (14) (2005), 1411.

$7 \quad$ Paul A. Offit, M.D., The Cutter Incident: How America's First Polio Vaccine Led to the Growing Vaccine Crisis (New Haven: Yale University Press, 2005), 79.

8 Robert Gallo, M.D., Virus Hunting: AIDS, Cancer, and the Human Retrovirus: A Story of Scientific Discovery (New York: Basic Books, 1991), 29.

9 As quoted in Paul A. Offit, M.D., The Cutter Incident: How America's First Polio Vaccine Led to the Growing Vaccine Crisis (New Haven: Yale University Press, 2005), 81.

10 Paul A. Offit, M.D. "The Cutter Incident, 5o Years Later." The New England Journal of Medicine 352 (14) (2005), 1411. For information on Paul A. Offit, see, www.paul-offit.com (accessed July 12, 2020). In terms of polio, the disease reached a peak in $195^{2}$ in the United 
In light of the COVID-19 pandemic, with its many significant political and social implications, discussion of the Cutter Incident illuminates potential problems concerning vaccine development. The U.s. government's program, "Operation Warp Speed," the private-public partnership to create a vaccine for the SARs$\mathrm{CoV}-2$ virus and the CoviD-19 disease it causes, is widely regarded, and even relied upon, as a solution with global consequences. ${ }^{11}$ Yet, Operation Warp Speed is also a program with limitations and these may be better understood with historical contextualization stemming from the Cutter Incident in 1955 .

\section{Sources and Organization}

This article focuses on the Cutter Incident and it describes how problems in the past may illuminate contemporary and future challenges in either immunizing against or treating COVID-19. At a time when a vaccine is anticipated by billions of individuals, we may better prepare for unanticipated and anticipated problems that lay ahead by looking at past problems. The past does not invariably offer comfort, yet it may help readers realistically appraise current efforts to mitigate current and future pandemics. Recent examples may help. In terms of the AIDS epidemic, as an example in recent history, lack of coordinated research to find a causal agent, let alone effective treatments, initially led to failure. According to Robert Gallo M.D, the former Chief of the Laboratory of Tumor Cell Biology at the National Institute of Health, the inability "to make sure that work began simultaneously on the opportunistic infections that accompanied AIDS (caused by HIV) angered many who could not understand how the wealthiest and most health-conscious nation in the world did not immediately undertake an organized effort."12 This paper seeks to help explain

States. See C.J. Howe and R.B. Johnston. "Options for Poliomyelitis Vaccination in the United States: Workshop Summary." National Academy of Sciences, Institute of Medicine Vaccine Safety Forum. (Washington, D.c., National Academies Press, 1996).

11 SARs-CoV-2 is the virus that causes the disease CoviD-19. Viruses are named by the International Committee on Taxonomy of Viruses (ICTV) whereas diseases are named by the World Health Organization in the International Classification of Diseases (ICD). In this article, COVID-19 will be used throughout with the intent that the reader may acknowledge the scientific difference between virus and related disease. For more on the relationship between SARS-CoV-2 and COVID-19, see the World Health Organization's report on this subject at:https://www.who.int/emergencies/diseases/novel-coronavirus-2019/technicalguidance/naming-the-coronavirus-disease-(covid-2019)-and-the-virus-that-causes-it (accessed September 5, 2020).

12 Robert Gallo, M.D., Virus Hunting: AIDS, Cancer, and the Human Retrovirus: A Story of Scientific Discovery (New York: Basic Books, 1991), 321-322. 
how obstacles, many created by the Cutter Incident, affects the United States' capability to confront the CoviD-19 pandemic and the United States' lack of a robust vaccine development infrastructure prior to January 2020.

Sources used, and other relevant literature consulted for this paper, merits brief discussion. Historian and Director of the Division of Medical Humanities at New York University, David M. Oshinsky was awarded the 2006 Pulitzer Prize and 2005 Hoover Presidential Book Award for Polio: An American Story. ${ }^{13}$ Oshinsky's work recounts and discusses the Cutter Incident, but in a limited way within the larger trajectory of polio's significant and deadly role in U.s. History. A 2013 lecture on polio recorded for C-Span also briefly mentions the Cutter Incident, but it does so in the context of discussing Oshinsky's book. ${ }^{14}$ Medical journals continue to assess polio, but primarily in terms of potential risks of a contemporary outbreak and vaccine availability. ${ }^{15}$ As an example, a 1996 Institute of Medicine Vaccine Safety Forum workshop historical summary of polio in the United States mentioned the peak incidence of polio in 1952, when 20,00o cases of paralytic poliomyelitis occurred. This summary acknowledged Salk's polio vaccine - technically known as an inactivated vaccine (IPV) - and it confirms the rapid licensure of the Salk vaccine in $1955 \cdot{ }^{16}$ However, what became known as the "Cutter Incident" is not mentioned in the 1996 Institute Forum study. In contrast, Paul Offit's 2005 book on the Cutter Incident remains the most detailed study of the subject, especially when augmented

13 David M. Oshinsky, Polio: An American Story (New York: Oxford University Press, 2005). Chapter 13, "The Cutter Fiasco," provides a 23-page narrative.

14 C-Span 3, American History TV. See "Lectures in History: Polio Epidemic in the U.s." aired April 9, 2013, presented by Sally McMillan, Davidson College, Davidson, North Carolina. McMillan centers her lecture around a discussion of Oshinsky's book and she addresses four key themes in the lecture: philanthropy for public health initiatives; medical research; scientists and personalities; and ethical issues of testing.

15 As an example, a Public Health Report published in 2012 focuses on 2010 as a starting year to assess expected changes in the U.s. population immunity profile. See Kimberly M. Thompson, Wallace, Tebbens, Smith, Barskey, Pallansch, Gallagher, Alexander, Armstrong, Cochi, and Wasskilak, "Trends in the Risk of U.s. Polio Outbreaks and Poliovirus Vaccine Availability for Response," Public Health Report, 127 (1) (2012), 23-37.

16 C.J. Howe and R.B. Johnston. "Options for Poliomyelitis Vaccination in the United States: Workshop Summary." National Academy of Sciences, Institute of Medicine Vaccine Safety Forum. (Washington, D.C., National Academies Press, 1996). The large number of 20,00o known cases is significant. According to Howe and Johnston, "one case of paralytic poliomyelitis theoretically can represent hundreds of individuals infected with the virus. Estimates vary from 50 to 1,000 subclinical infections for each case of paralytic diseases diagnosed." Additionally, in contrast to inactivated vaccine for polio including Salk's IPV, longstanding U.s. policy has directed the use of a live attenuated vaccine (OPV). 
with Oshinsky's work, which explains the prominent place Offit's scholarship assumes as a key source for this article.

This paper is organized into three sections. The first section recounts the Cutter Incident in 1955. The second section explores consequences and implications stemming from the Cutter Incident in the years following the incident. As shown, there were seven reasons why the Cutter Incident occurred. The findings from the disaster greatly improved subsequent vaccines for Polio. Yet, there were also many negative consequences, not only in victims' deleterious health resulting from the inactivated vaccine, but also in terms of subsequent legal liability for companies developing vaccines in the decades following the 1955 incident. The third and final section of the paper explores the broader contemporary relevance of the Cutter Incident for vaccine development for CoviD-19. In many ways, the Cutter Incident powerfully determined the future of vaccine development, including those underway for Covid-19.

Moving forward to 2020 and prior to the onset of COVID-19, the vaccine development sector within major pharmaceutical industry was surprisingly fragile. In early 2001, vaccine development and related products constituted only $1.5 \%$ of global pharmaceutical sales and vaccine shortage supplies in 2001 and 2002 affected 8 of 11 routine childhood vaccines. ${ }^{17}$ Massive U.s. government investment through Operation Warp Speed seeks to correct this by invigorating the vaccine industry. Yet, it appears that the strenuous and costly effort to create a vaccine for CoviD-19 is mostly a case of catching up and a failure to maintain a healthy vaccine industry pre-COVID-19. Operation Warp Speed, in fact, is busy infusing a weak industry prior to 2020 because vaccines previously failed to generate financial profit, even though they have increased global lifeexpectancy. ${ }^{18}$

In ways revealed by Operation Warp Speed, the reason why most vaccines before 2020 were produced by only four contemporary companies (Aventis Pasteur, GlaxoSmithKline, Merck, and Wyeth) may be traced back to April 1955 and the Cutter Incident. Pharmaceutical companies largely abandoned vaccine development after the Cutter Incident because legal liability destroyed the cost-effectiveness of bringing new products to market. The Cutter Incident did provide critical information for improving subsequent vaccines in the mid to late 1950s, but the incident also reveals why demands for a speedy and effective vaccine for CoviD-19 deserve to be tempered. Simply, it is difficult for vaccine

17 "Financing Vaccines in the 21st Century: Assuring Access and Availability," National Center for Biotechnology Information, U.s. National Library of Medicine (2004).

18 Noah Weiland, Denise Grady and David E. Sanger, "Pfizer Gets \$1.95 Billion to Produce Coronavirus Vaccine by Year's End," The New York Times, July 22, 2020. 
development to catch up and this is especially true given the complexity, reach, and largely unanticipated nature of the CoviD-19 pandemic. The Cutter Incident also demonstrates why non-vaccine treatment for the disease may be as important as development of an effective vaccine that - should it be created deserves to be equitably available for the world's population of 7.5 billion individuals.

On top of these issues, demand for a vaccine is not only intense, it is deeply politicized within domestic political arenas and within a geopolitically tense era of growing great-power competition. In terms of covid-19's effect on the United States, on July 15, 2020 U.s. Senate Majority leader, Mitch McConnell explained, "I think the straight talk here that everyone needs to understand is this: COVID-19 is not going away until we get a vaccine."19 As of late summer 2020, therefore, over 160 companies-other than the big four producers mentioned earlier-emerged to begin development of a vaccine, yet effective vaccines take long periods to develop. Merck's successful and most recent vaccine for Mumps took four years to develop and its proven vaccine for Ebola required five years of research and testing. ${ }^{20}$ The Cutter Incident demonstrates how rushing this process unleashed unanticipated problems which deserve consideration in light of contemporary vaccine development

Operation Warp Speed is a tall order and because it is serious and important, it deserves contextualization as to why it is has many challenges. Understanding the consequences of the Cutter Incident helps explain these and may improve our understanding of vaccines' critical role in and relationship to public health. ${ }^{21}$ In addition, U.s. government officials' assurances that they are racing to create a vaccine "at warp speed" does not address whether or not people will actually decide to get vaccinated. Distrust of an effective vaccine among African-American communities, for example, remains high. ${ }^{22}$

Briefly, it is important to describe Operation Warp Speed in more detail. According to Dr. Peter Hotez, a vaccine researcher at Baylor College of Medicine, "All the hype makes it seem like a miracle is around the corner, that is just not the case. This is not going to be a quick fix. This is going to take years to sort

19 "Mitch McConnell, unlike Trump, says he has 'total' confidence in Anthony Fauci," Louisville Courier Journal, July 15, 2020.

20 "Merck CEo Ken Frazier and Tsedal Neely talk covid Vaccines, Racism and why leaders need to really act," July 10, 2020. https://www.youtube.com/watch?v=KJMekwILAJo\& feature=youtu.be (accessed July 11, 2020).

21 For up-to-date progress of efforts to develop Coronavirus treatment, see The New York Times, Coronavirus Vaccine Tracker.

22 Jan Hoffman, "Mistrust of a Coronavirus Vaccine Could Imperil Widespread Immunity," The New York Times, July 18, 2020. 
out."23 The U.s. government's $\$ 1.6$ billion dollar investment in vaccine manufacturer Novavax - allocated to develop a covid-19 vaccine - should give readers pause when considering the fact that Novavax has never brought a product to market. Investment in solutions is admirable, yet massive investment in an unproven company's potential product should is also sound alarm bells among those familiar with the Cutter Incident and its consequences. ${ }^{24}$ McConnell's call for a vaccine is unsurprising, yet existing evidence indicates that coviD19 remains a severe biomedical challenge to solve through vaccines, let alone through treatment. Until prevention through vaccination is assured, mitigating the disease entails implementing robust social measures and improving treatment for existing cases as the pandemic continues.

Other questions remain: why do we believe a vaccine for Covid-19 will be fully developed, especially when vaccines for other viruses, such as HIV, remain elusive? Why do we have faith that a vaccine will be effective, let alone equitably distributed should a verified and safe vaccine be created? The past plight of weak vaccine development in the United States, which Operation Warp Speed seeks to address, is only one consequence of the Cutter Incident in 1955. As this article demonstrates, this weakness not only contributed to the worst medical disaster in U.s. history, it also unleashed legal liability and related problems encumbering potential research. These obstacles, in turn, contributed to our contemporary vaccine-deficient predicament we desperately require to address to remedy COVID-19. The Cutter Incident should remind policy-makers, as well as historians, that carefully developed vaccines are only as good as the lots manufactured for the public consuming them. The Cutter Incident is valuable to revisit, not only because of its significant role affecting vaccine development in the past, but also because of its relevance among those demanding a CoviD-19 vaccine today in what is the most pressing pandemic in the first quarter of the 21st century.

\section{The Cutter Incident}

In 1952, polio reached peak incidence in the United States with 59,00o cases of paralytic poliomyelitis. ${ }^{25}$ Jonas Salk, a scientist who had worked on vaccines for

23 David D. Kirkpatrick, "Three Coronavirus Vaccine Developers Report Promising Results," The New York Times, July 21, 2020.

24 Katie Thomas, “U.s. Will Pay \$1.6 Billion to Novavax for Coronavirus Vaccine," July 7, 2020, The New York Times.

25 Smithsonian National Museum of History, Behring Center Series, "The American Epi- 
influenza since 1941, confirmed that there were three strains of polio virus and he developed a vaccine by inactivating poliovirus-including all three types of virus - with formaldehyde. ${ }^{26}$ This critical process, inactivation, consisted of nine days of formaldehyde treatment which Salk determined effectively killed the active virus in his vaccine. Others, including Sven Gard, a virologist at the Karolinska Institute in Stockholm, disagreed with Salk's finding. Gard determined that at least twelve weeks of formaldehyde treatment were necessary for inactivation to run its full course. ${ }^{27}$

Despite Gard's findings, Salk moved ahead with his vaccine. By February 1954, protocols Salk developed for the manufacture of polio vaccine eventually filled fifty-five pages. In making the jump from trial to production, however, Salk demonstrated an unfounded faith that the precautions he personally took automatically extended to how manufacturers might produce the vaccine. Even though he was aware of the importance of effective inactivation, filtration, and other measures, "Salk believed that if pharmaceutical company scientists understood his theories, the details of manufacture were unimportant."28 Salk assumed that people would follow precautions as he intended and this did not occur. Instead, during mass production, Salk's fifty-five pages of vaccine production protocol were reduced to five and the Laboratory of Biologics Control, an organization within the National Institute of Health which deliberated over these protocols, moved quickly to license the polio vaccine.

The licensing process overseen by the U.s. government turned out to be a central point of failure in the polio vaccine fiasco in 1955 and haste played a major role. The entire discussion to license Salk's vaccine, in fact, lasted a mere 2.5 hours. During that tiny window of time, the Laboratory of Biologics Control's commission moved through material detailing Salk's vaccine consisting almost 2,0oo pages of complex information. It was clearly impossible that sufficient attention was given to the intricacy of Salk's vaccine. Yet, less than three hours later, the licensing process proceeded. On April 12, 1955, the U.s. govern-

demics." See https://amhistory.si.edu/polio/americanepi/communities.htm\#: :text=Epid emics\%2oworsened\%2oduring\%2othe\%2ocentury,and\%2ogrown\%2Dups\%20as\%2ow ell. (accessed June 2, 2020). See also Paul A. Offit, M.D., The Cutter Incident: How America's First Polio Vaccine Led to the Growing Vaccine Crisis (New Haven: Yale University Press, 2005), 31.

26 Paul A. Offit, M.D. "The Cutter Incident, 5o Years Later." The New England Journal of Medicine $35^{2}$ (14) (2005), 1411. The three types of poliovirus are Mahoney, MEF-I, and the Saukett Strain.

27 Paul A. Offit, M.D., The Cutter Incident: How America's First Polio Vaccine Led to the Growing Vaccine Crisis (New Haven: Yale University Press, 2005), 43.

28 Ibid., 47 . 
ment licensed polio vaccine production to five companies, including Cutter Laboratories. ${ }^{29}$ If there was ever a case of pondering "minimum requirements" at high speed-especially those guiding a critical verification procedure-it was this step that led to the Cutter Incident.

According to Paul Offit, in contrast to the speedy process undertaken in April 1955, it now takes at least a year to license a vaccine and accompanying documentation for this procedure averages 60,000 pages. ${ }^{30}$ Given this length of time, it is difficult to account for the belief that the entire cycle of contemporary vaccine development in 2020, including careful testing and licensing, may be safely conducted in less than a year. The Cutter Incident, above all, was a failure in government supervision of pharmaceutical companies and the rush to bring a polio vaccine to market drove poor decision-making. There were understandable reasons for a desire to find a remedy and to find one fast. In 1955, a national poll "found that polio was only second to the atomic bomb as the thing Americans feared the most."31 A desperate and high-speed chase for a cure was obvious, yet it was also fraught with the potential for disaster.

Vaccine history, ranging from Edward Jenner's pioneering smallpox vaccine to Louis Pasteur's rabies vaccine, is mostly driven by existential concerns and success is desperately sought. Viruses' and other diseases' dominance over humans does much to explain the comparatively short-life spans of humans before the 2oth century. Modern medical science is easy to take for granted. It was only in 1900 that "the United States made its historical entry into microbiology when the army surgeon Walter Reed and his group, by establishing the cause of yellow fever, were the first to discover a disease-causing virus in humans." Their work led to a yellow fever vaccine and, by the mid-193os, a vaccine created by Max Theiler and Hugo Smith became only the third in human history. $^{32}$

In effect, the effort to create vaccines for viruses moved at warp speed already in the first few decades of the twentieth century. In the case of Salk's efforts in 1952, he and other scientists, including Albert Sabin, advanced vaccine science forward with great urgency because polio was a killer. In 1916, two years before influenza killed 675,00o Americans, the largest polio epidemic recorded raged through New York City, paralyzing 9,ooo people and

\footnotetext{
29 Ibid., 61.

$30 \quad$ Ibid., 62.

31 Ibid., 32.

32 Robert Gallo, M.D., Virus Hunting: AIDS, Cancer, and the Human Retrovirus: A Story of Scientific Discovery (New York: Basic Books, 1991), 2.
} 
killing 2,400 others. ${ }^{33}$ When another polio epidemic raged in the early 1950s, these precedents shaped public perception of this deadly disease. In addition, the public knowledge that President Franklin D. Roosevelt suffered from polio proved that the virus did not discriminate across class-lines. Moreover, the fact that a preponderance of victims included young children stoked fear as well.

In April 1955, therefore, significant demand for Salk's mass-produced vaccine existed. As a result, millions of doses of polio virus vaccine were delivered across the United States by the latter half of April 1955 before the paralyzing virulence of the vaccine was discovered. A majority of these doses were recalled, but not before 380,000 children had been inoculated. The final toll included the infection of 220,00o people with live poliovirus with 164 paralyzed, most severely, and 10 deaths. ${ }^{34}$ The problem centered on the fact that the vaccine Cutter Laboratories produced contained the most virulent strain, called the Mahoney strain, of the three types Salk discovered earlier in 1952. Cutter Laboratories, it was quickly determined, did not follow the same production protocols Salk developed. Because of insufficient government regulations that demanded that vaccine manufacturers adhere to Jonas Salk's guidelines for inactivating the live virus, Cutter's production failed to kill the virus in the vaccine. Worse, vaccine doses that Cutter and other companies deemed safe were, in fact, "approved as safe by the federal government" even though these virulent doses still contained live virus. ${ }^{35}$

How Did the Cutter Incident Happen?

Seven problems converged to unleash the Cutter Incident. In a manner similar to synergistic problems found in intelligence failures, this convergence not only led to the harm inflicted on victims of the vaccine, but also to serious political fall-out. The United States Secretary of Health, Education and Welfare and the NIH Director resigned while the director of the microbiology institute was fired. In a concise assessment of the medical and political consequences, Gallo assessed that "the only surprising thing was that the consequences weren't even more horrible than they actually were." 36 In the months following the reve-

Paul A. Offit, M.D., The Cutter Incident: How America's First Polio Vaccine Led to the Growing Vaccine Crisis (New Haven: Yale University Press, 2005), 9.

34 Ibid., 89.

35 Ibid., 97 .

36 Robert Gallo, M.D., Virus Hunting: AIDS, Cancer, and the Human Retrovirus: A Story of Scientific Discovery (New York: Basic Books, 1991), 29. 
lation that live polio was released to the public, seven explanations for the disaster emerged.

First, the Mahoney strain was chosen because it created the greatest amounts of antibodies after tests. Other type 1 strains were used in several European countries with no problems, but all five U.s. companies use of Mahoney increased inactivated vaccine virulence. Second, Cutter Laboratories' filtration process had three problems. The leading issue with filtration occurred because polio virus was cultivated in cells. When excessive cell debris remained, due to inadequate filtration, the virus was effectively shielded by debris from the formaldehyde used to inactivate, or kill, the virus. A related but secondary factor included the use of glass filters instead of more effective "Seitz" filters because "glass filters occasionally allowed tiny amounts of cell debris (with free-riding virus) to pass through." ${ }^{37}$ The reason glass filters were chosen centered on the goal of shortening filtration times to increase speed of vaccine manufacture. The specific glass filters Cutter employed, moreover, were inferior to others, such as those used by Glaxo in England, a company which successfully created polio vaccine without residual virus. ${ }^{38}$

Third, federally required safety tests were inadequate and in a state of flux in April 1955. Cutter, in fact, followed all testing requirements and this helped enable the company to avoid charges of negligence in subsequent lawsuits arising from the incident. Yet, overall testing was sprawling and included several sub-issues. These included the use of insufficiently large test samples, faulty processes for testing on monkeys, and changes in cell tissue culture tests which cumulatively contributed to a moving set of testing targets. Fourth, "Cutter let filtered virus sit in the refrigerator for long periods before inactivating it" and this caused "cell debris to form on the bottoms of flasks" from which vaccine was produced. ${ }^{39}$

The fifth problem was that Cutter did not precisely determine how much time was required to inactivate polio virus with formaldehyde. Salk's guidelines for inactivating the virus were stated in his guidelines, but these were not enforced adequately during manufacturing of the vaccine and Cutter "never determined when live virus was first eliminated and couldn't determine how long to treat the virus with formaldehyde." 40 Salk's guidelines, in effect, were

Paul A. Offit, M.D., The Cutter Incident: How America's First Polio Vaccine Led to the Growing Vaccine Crisis (New Haven: Yale University Press, 2005), 106. Offit's discussion of these seven factors are discussed in pages $105^{-113}$.

38 Ibid., 108.

39 Ibid., no.

40 Ibid., 112. 
based on a theory of inactivation that was neither mandated nor enforced by the federal government in its goal to issue a polio vaccine quickly. It is difficult to understand how this did not constitute negligence except for the likelihood that since it was determined that the safety of Salk's vaccine was acknowledged during test trials, that this assumption was also extended to Cutter's mass production of vaccine. Ultimately, this deficiency was paid for by ist and and graders and their families.

The sixth issue that contributed to the Cutter Incident was Cutter's failure to report any problems. Again, it is difficult to see how Cutter was not negligent in this, especially because evidence surfaced that the company knew that its process only inconsistently killed the polio virus in their vaccines. As Offit documents, one-third of its produced lots failed safety tests but these failures were insufficiently reported. ${ }^{41}$ In fact, Cutter never made four consecutive lots that did pass safety tests. The central problem is that testing was not sufficiently regulated and this was most likely the result of the emerging nature of Salk's theory of inactivation and certainly in its poor implementation during mass production. Poor U.s. government oversight and regulation, of course, could hardly fix Cutter's failures: even if unintentional, the Cutter Incident was a medical case of the fox watching the hen house. This overall problem of government failure likely absolved Cutter of greater legal challenges than those the company eventually encountered.

Related to a failure to report, the seventh contributing factor for the incident was that the federal government did not even know Cutter was having problems. ${ }^{42}$ Again, for a government responsible for the safe licensure of vaccines, this was deeply problematic. This concluding factor, along with the issue of safety test design and regulation failure, arguably put the U.s. government in the crosshairs of responsibility for the Cutter Incident. The director of the National Institute of Health, National Microbiological Institute, the Surgeon General, and the Secretary of the Department of Health, Education, and Welfare, as mentioned, either resigned or were fired and this demonstrates known culpability. The warnings Bernice Eddy provided to the Laboratory of Biologics Control - the organization responsible for licensing the vaccine for production after safety tests - were "lost in the noise." Ultimately as Paul Offit concluded, "the federal government was in the best position to avoid the Cutter tragedy" and it failed. ${ }^{43}$

\begin{tabular}{ll}
\hline 41 & Ibid., 112-113. \\
42 & Ibid., 113. \\
43 & Ibid., 119.
\end{tabular}


Instead of an even greater reckoning for the federal government, the incident's most significant legacy - for pharmaceutical companies at leastemerged in the form of legal liability without fault. ${ }^{44}$ As Offit documents with the incisiveness of an articulate lawyer, this legal development centered on the fact that Cutter Laboratories was liable, but that it was not negligent because it followed protocols, faulty as they were, that were instituted according to scientific knowledge at the time. In fact, Cutter followed prescribed guidelines and only released product that passed recommended safety tests. It is clear that the United States government, since it was responsible for vaccine regulation, absolved itself of far greater liability. After all, who else could hold the U.s. government accountable? Numerous government officials were fired, but Cutter, even when scapegoated, miraculously avoided a full-legal broadside.

Along with politicized attempts to lay blame on Vice-President Richard Nixon, because of his past representation of California in the U.s. Congress, Berkeley-based Cutter Industries not only survived but eventually prospered. ${ }^{45}$ In 1957, Cutter was sued for negligence and breach of implied warranty, but the ruling in Gottsdanker vs. Cutter Laboratories determined that Cutter was not negligent because most companies producing the polio vaccine had problems inactivating the virus in their vaccines. ${ }^{46}$ Wyeth, for example, also created vaccine that paralyzed and killed several children, but the company's problems were obscured until later. It was determined, in the end, that Cutter violated the implied warranty that its product would be effective when used as directed. The Gottsdanker case, however, would have important and negative consequences for subsequent vaccine development. The Gottsdanker ruling enabled juries to "find companies financially responsible (liable) for their products without finding them negligent in the production or design of those products (i.e., liability without fault)." ${ }^{\prime 47}$ The idea that proof of negligence is not required to determine liability would constrain vaccine development and the legal subject remains contentious. ${ }^{48}$

\footnotetext{
44 Ibid., 179 .

45 Ibid., 117.

46 Paul A. Offit, M.D. "The Cutter Incident, 5o Years Later." The New England Journal of Medicine 352 (14) (2005), 1411.

47 Ibid.

48 The legal issue of liability without negligence (fault) is discussed in Gregory C. Keating, "Is There Really No Liability Without Fault? - A Critique of Goldberg \& Zipursky," Fordham Law Review Res Gestae, 85, (2016). For Offit's discussion, see chapter 8 in The Cutter Incident: How America's First Polio Vaccine Led to the Growing Vaccine Crisis (New Haven: Yale University Press, 2005).
} 
After the Cutter Incident, the U.s. government instituted more rigorous regulations for all vaccines, including procedures for filtration, storage, and safety testing. Yet, the cost-benefit analysis associated with severe liability laws which emerged in the years after the Cutter Incident continue to affect vaccine development. In the United States, prior to investments made through Operation Warp Speed - to the tune of $\$ 10$ billion-vaccines were not invariably perceived as a profitable venture for pharmaceutical companies. According to a 2003 study, "Vaccines are a very small enterprise relative to the pharmaceutical industry overall: vaccine revenues constitute only 1.5 percent of global pharmaceutical sales," and, in the three decades after the Cutter Incident, "the number of firms supplying routine vaccine to the United States dwindled to five companies." 49

Vaccine production is capital intensive, requires skilled labor, and requires expensive equipment. Further, according to a 2017 article in the journal Vaccine, "while vaccine manufacturing may prima facie seem an economic growth opportunity, the complexity and high fixed costs of vaccine manufacturing limit potential profit."50 The current preoccupation with Operation Warp Speed, and the urgency of CoviD-19, should not blind individuals of this bigger picture that vaccine development and production is immensely complex.

Once the Cutter Incident was finally resolved, the incidence of polio in the United States decreased significantly. A total of 400 million doses of safe and verifiably inactivated polio vaccine were eventually administered by $1962 .{ }^{51}$ Yet, other, longer-term harm was inflicted on the vaccine manufacturing sector and pharmaceutical companies were increasingly reluctant to produce products that rarely pulled in large profits. When vaccine regulation moved from the National Institute of Health to the Federal Drug Administration in 1972, an irony followed: vaccine regulations grew to the point that vaccines were quickly held to a higher standard than almost any medical product created for children and vaccines eventually reached "a record of safety matched by no other product." ${ }^{\prime 2}$ Vaccine safety, thus, has increased dramatically. Yet, as a consequence, liability-related legal issues decreased potential profits and this

49 Institute of Medicine Committee on the Evaluation of Vaccine Purchase Financing in the United States, Financing Vaccines in the 21st Century: Assuring Access and Availability. (Washington D.C.: National Academies Press), 2003.

50 Plotkin, Stanley. et al., "The complexity and cost of vaccine manufacturing-An overview." Vaccine 35 (2017), 4064-4071.

51 Paul A. Offit, M.D., "The Cutter Incident, 5o Years Later," The New England Journal of Medicine 352 (14) (2005), 1411.

52 Paul A. Offit, M.D., The Cutter Incident:How America's First Polio Vaccine Led to the Growing Vaccine Crisis (New Haven: Yale University Press, 2005), 178-179. 
factor constrained vaccine development which has progressed at a snail's pace for the last two decades, at least until 2020 when Operation Warp Speed was announced. Before addressing this further, it is worthwhile to consider briefly what happened to Cutter Laboratories.

After 1955, Cutter, which also created the bug-spray bearing its name, endured sixty court cases with plaintiff claims totaling $\$ 12$ million. Yet, Cutter emerged mostly unscathed and settled its cases by paying out $\$ 3$ million, of which $\$ 2$ million was covered by Cutter's insurance. ${ }^{53}$ By 1961 , the company's total revenue exceeded $\$ 24$ million. This growth came, in part, when its analgesic product for mitigating pain generated massive revenue after it was licensed to Bristol-Meyers who marketed the product as Excedrin. ${ }^{54}$ Cutter, in short, made a fortune killing pain and was eventually purchased by the German pharmaceutical company Bayer in $1974 .{ }^{55}$

The Cutter Incident is rarely remembered today, except by victims of polio, their families, and physician-scholars, such as Paul A. Offit. Fortunately, since 1988 world-wide cases of polio have decreased by $99 \%$, but polio is not entirely eradicated. Between 1980 and 1992, a total of 109 cases of vaccine-associated polio (VAPP) were reported in the United States, out of a total of 262 million distributed doses; this is a risk of 1 in 2.4 million. ${ }^{56}$ Still, even as of 2006 , pediatricians continued to publish decision analysis in the event a polio outbreak occurred again in the United States. ${ }^{57}$ It is a disease that is under control, but it is not extinguished. CoviD-19 is a serious problem, to be certain, but history shows that human history is one in which it continuously confronts numerous calamities. It is helpful, therefore, to gather whatever lessons emerge from the past. "The longer you can look back," as Winston Churchill suggested, "the farther you can look forward."58

53 Ibid., 166.

54 Ibid., 168.

55 Bayer History, “Oil Crisis and Consolidation (1974-1978)," https://www.bayer.com/en/1974 -1988.aspx (accessed June 12, 2020).

56 C.J. Howe and R.B. Johnston. "Options for Poliomyelitis Vaccination in the United States: Workshop Summary." National Academy of Sciences, Institute of Medicine Vaccine Safety Forum. (Washington, D.C., National Academies Press, 1996).

57 Pamela C. Jenkins, John F. Modlin, "Decision Analysis in Planning for a Polio Outbreak in the United States," Pediatrics (2006); On current cases of Polio, see World Health Organization's Newsroom: https://www.who.int/news-room/q-a-detail/does-polio-still-exist-is-it -curable (accessed June 2, 2020).

$5^{8}$ International Churchill Society, https://winstonchurchill.org/resources/quotes/quotes-fa lsely-attributed/ (accessed June 12, 2020). 


\section{$5 \quad$ The Contemporary Relevance of the Cutter Incident}

Vaccines have prevented disabling and deadly diseases in the United States for decades. Despite the alarm that the Cutter Incident created, vaccines have also proven to be historically low-cost and represent, according to a 2003 Institute of Medicine report, "one of the outstanding bargains in health care."59 Despite these factors, according to the same report, the vaccine industry was "surprisingly fragile" in 2003 and this weakness - which has grown over the last seventeen years - now necessitates the large-scale and significant financial outlays to effectively "catch-up" through creating and funding Operation Warp Speed to remedy COVID-19's extensive reach. ${ }^{60}$ Through the CARES Act, the U.s. government has allocated almost $\$ 10$ billion to Operation Warp Speed and the program is multi-faceted. ${ }^{61}$ The primary concern this paper seeks to raise, as the Cutter Incident demonstrated, is that the urgency to create a solution is not only driven by medical necessity. Solutions are also driven by political concerns that may create unexpected and deleterious outcomes with long-term consequences with significant financial cost and social disruption. Science, however, should never become politics' handmaiden, even when immense political pressure is applied to create a solution. Before 2020, the Cutter Incident contributed to the fragility of the vaccine industry. Yet, can Operation Warp Speed safely push vaccine development into the future to address CoviD-19? Operation Warp Speed reveals problems that are not always strictly scientific in nature.

Contemporary reporting, with headlines such as "Mistrust of a Coronavirus Vaccine Could Imperil Widespread Immunity," indicates widespread concerns that individuals may not choose a vaccination, even if one is made available. ${ }^{62}$ This concern may center on the fact that vaccine development for covid19 is rushed for political purposes instead of safely developed according to scientific-based norms for effective vaccines that have historically required several years to develop. These concerns reached such intensity in September 2020 that several drug companies competing to develop coronavirus vaccines

59 Institute of Medicine Committee on the Evaluation of Vaccine Purchase Financing in the United States, Financing Vaccines in the 21st Century: Assuring Access and Availability. (Washington D.C.: National Academies Press), 2003.

6o Ibid.

61 For comprehensive information about Operation Warp Speed, see HHS.gov, "Fact Sheet: Explaining Operation Warp Speed." https://www.hhs.gov/coronavirus/explaining-operati on-warp-speed/index.html. (accessed September 2, 2020).

62 Jan Hoffman, "Mistrust of a Coronavirus Vaccine Could Imperil Widespread Immunity," The New York Times, July 18, 2020. 
planned to cooperate "to reassure the public that the companies will not seek a premature approval of vaccines under political pressure."63

U.S. Senate Majority Leader, Mitch McConnell noted that the COVID-19 pandemic will continue until there is a vaccine. However, this relies on assumptions that a safe vaccine will be eventually created, but if so, when? 2021? 2022? According to Merck CEO, Ken Frazier, the current record for Merck's vaccine for Mumps took four years and a proven vaccine for Ebola took almost six years. In Frazier's assessment of vaccine development, the most pressing component is time. ${ }^{64}$ Time, also the most important commodity humans have, may not be usefully compressed to deliver a vaccine to market, no matter how loud politicians and the public clamor for a solution. This is a central lesson from the Cutter Incident worth bearing in mind as Operation Warp Speed moves forward. The shortfalls in vaccine production, as demonstrated through the Cutter Incident, should not happen again. In the end, the Cutter Incident deserves to be remembered because it shows the value of patience and it shows the importance of safe testing for a vaccine that should be equitably distributed if one is developed.

\section{6}

\section{Conclusion}

The Cutter Incident provides lessons in what to avoid and it serves as an egregious example of how things may go wrong in the development and production of vaccines. It is critical to address the fact that contemporary efforts to create a vaccine for COVID-19 do not include attempts to use an inactivated, i.e., killed virus, within the vaccine. It is also important to manage expectations. In the event a vaccine is developed, according to the N I H's Anthony Fauci, a $70 \%$ effectiveness rate would mark a great success. ${ }^{65}$ Undeniably, an effective vaccine is the quickest way to reduce the CoviD-19 pandemic, but, as Fauci knows better than any historian, solutions may also come from other forms of cancer research and other fields of scientific study. Applying the utility of history

63 Katie Thomas, Noah Weiland, and Sharon LaFraniere, "Pharma Companies Plan Joint Pledge on Vaccine Safety," The New York Times, September 4, 2020.

64 "Merck CEo Ken Frazier and Tsedal Neely talk covid Vaccines, Racism and why leader need to really act," July 10, 2020. https://www.youtube.com/watch?v=KJMekwILAJo\&\&eatu re=youtu.be (accessed July 15, 2020).

65 "Dr. Anthony Fauci on What it Will Take to Beat the Pandemic," Harvard Business School, "HBR Quarantined," July 2, 2020. https://www.youtube.com/watch?v=NCZM5QQ2_Wo (accessed July 8, 2020). 
to possibilities that have not been considered before while remaining openminded about their potential contribution, is a lesson we may usefully gather from other epidemics. ${ }^{66}$

It is worth pointing out that Operation Warp Speed is clearly fraught with technical and scientific challenges. As history shows, such obstacles are not only difficult to overcome, but solutions for them are potentially dangerous when pushed in haste because of politicization. When Stanley C. Erck, Novavax's president and chief executive described in July 2020 how his company's deal with the U.s. government "would allow Novavax to begin manufacturing the vaccines before the company concludes late-stage clinical trials," the Cutter Incident should come to mind as a warning. ${ }^{67}$ In terms of those doubting the utility of vaccines at all, one effective way to address the stridency of antivaxxers' campaigns against vaccination may include simply providing clear and comprehensive information and history may help provide clarity in such an effort. Historians may contribute, therefore, to an improved information environment by highlighting how the past affects the plight of people enduring the Covid-19 pandemic today. The Cutter Incident should remind us, in the end, that one of the most consequential causes of the disaster originated in the desire and rush to create a solution.

66 See Robert Gallo, M.D., Virus Hunting: AIDs, Cancer, and the Human Retrovirus: A Story of Scientific Discovery (New York: Basic Books, 1991), 304. In the case of HIV, the development of pharmaceutical treatments constituting reverse transcriptase inhibitors were among the earliest treatments. Gallo also discusses the development of antiviral immunotherapy, the use of a vaccine to stimulate an anti-HIV immune response, "not to prevent an infection but to hold back the virus in an already infected person." Ibid., 309 .

67 Katie Thomas, “U.s. Will Pay \$ 1.6 Billion to Novavax for Coronavirus Vaccine," July 7, 2020, The New York Times. 